\title{
Effect of rhythmic-musical exercises on visual perception and executive function of 8-10 years old children with dyslexia
}

\author{
Ehteram Ghasemi ${ }^{1}$, Rokhsareh Badami ${ }^{2 *}$ iD, Zohre Meshkati \\ 1. MA of Motor Behavioral, Faculty of Physical Education and Sports Science, Islamic Azad University of Isfahan (Khorasgan), \\ Esfahan, Iran \\ 2. Associate Professor of Physical Education, Faculty of Physical Education and Sports Science, Islamic Azad University of Isfahan \\ (Khorasgan), Esfahan, Iran
}

Recieved: 11 Oct. 2017

Revised: 27 Aug. 2018

Accepted: 27 Sep. 2018

\section{Keywords}

Rhythmic-musical exercises

Visual perception

Executive function

Dyslexia

Corresponding author

Rokhsareh Badami, Associate Professor of Physical Education, Faculty of Physical Education and Sports Science, Islamic Azad University of Isfahan (Khorasgan), Esfahan, Iran

Email: Rokhsareh.badami@khuisf.ac.ir

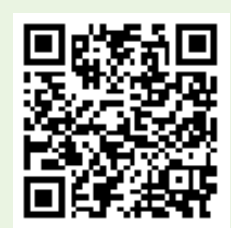

doi.org/10.30699/icss.21.2.83

\section{Abstract}

Introduction: This study aimed to investigate the effect of rhythmic-musical exercises on visual perception and executive function of 8-10 years old children with dyslexia. Methods: The research design was quasi-experimental with pre-test and post-test. The participants included 23 children with dyslexia aged between 8 and 10 years who were selected through convenience sampling and, after matching, were randomly assigned into the experimental and control groups. The experimental group participated in rhythmic-musical exercises for 12 weeks (3 sessions per week), but the control group did not receive any intervention during this time. Prior and following the intervention, visual perception skills were measured by the Test of Visual-Perceptual Skills-Revised (TVPS-R) and the executive functions by the Wisconsin Card Sorting Test (WCST). The data were analyzed using covariance test.

Results: The Findings of the analyses indicated that the rhythmic-musical exercises improved the visual perception skills and executive functions of the children with dyslexia. Conclusion: Based on the results of the present study, it might be concluded that the rhythmic-musical exercises can be used to enhance the visual perceptual skills and executive functions of children with dyslexia. 


\title{
اثر تمرينات ريتميك_موسيقيايى بر ادراك بينايى و كاركرد اجرايى كودكان A-ــا سال نارساخوان
}

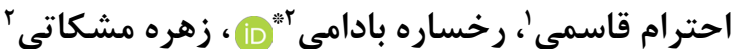

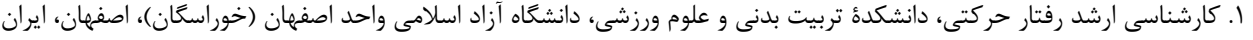

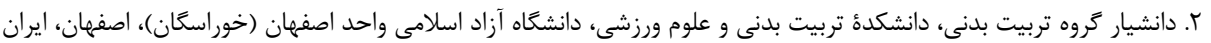

\section{asus}

مقلدمه: هدف از انجام تحقيق حاضر، تأثير تمرينات ريتميك_موسيقيايى بر ادراك بينايى و كاركردهاى اجرايى كودكان 1 تا • • سال نارساخوان بود. روش كار: اين تحقيق به روش نيمه تجربى و به صورت ميدانى و با طح پيش آزمون-یّ آزمون انجام شد. شركت كنندكان اين يُوهش را بr نفر از كودكان •l-1 سال داراى اختلال نارساخوانى تشكيل مى دادند كه به صورت در دسترس انتخاب و پِس از همتاسازى در دو گروه آزمايش و كنترل قرار گرفتند. گروه آزمايش، به مدت זا هفته در تمرينات ريتميك_موسيقيايى (ץ جلسه يك ساعته در هفته) شركت كردند و گروه كنترل در طول دورة تمرينات هيج كونه مداخلهاى دريافت نكردند. قبل و بعد از دورة مداخله، مهارت ادراك بينايى توسط آزمون ادراك بينايى Gardner و كاركرد اجرايى توسط آزمون دستهبندى كارت ويسكانسين سنجيده شد و دادهها با استفاده از آزمون تحليل كواريانس

$$
\text { مورد تجزيه و تحليل قرار كرفت. }
$$

يافته ها: نتايج تجزيه و تحليل يافتهها نشان داد كه تمرينات ريتميك_موسيقيايى باعث افزايش مهارتهاى ادراى بينايى و كاركردهاى اجرايى كودكان نارساخوان مىشود. نتيجه گَيرى: با توجه به يافتههاى يروهش حاضر مىتوان جنين نتيجه كرفت كه از تمرينات ريتميك_موسيقيايى مىتوان براى بهبود مهارتهاى ادراك بينايى و كاركرد اجرايى كودكان داراى اختلال نارساخوانى استفاده كرد.
دوريافت:

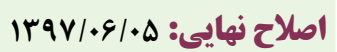

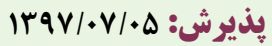
وازهنهاى كليدى تمرينات ريتميك_موسيقيايى

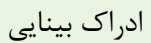

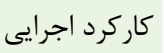
نارساخوان

نويسنله مسئول رخساره بادامى، دانشيار گروه تربيت بدنى، دانشكدة تربيت بدنى و علوم ورزشى، دانشعاه آزاد اسلامى واحد اصفهان (خوراسگان)، اصفهان، ايران ايميل:Rokhsareh.badami@khuisf.ac.ir

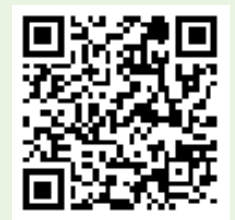

dol doi.org/10.30699/icss.21.2.83

مقدمه

كه ميزان شيوع نارساخوانى در بين دانش آموزان حدود • -1ه درصد است (Y). عمدهترين مشكلات كودكان مبتلا به ناتوانى خواندن عبارتند از حذف كلمه يا حروف، تحريف و اشتباه خواندن حروف يا كلمات، جانشينسازى حرف يا كلمه، ناتوانى در درك معنى كلمات، ناتوانى در استنباط مطالب خوانده شده، ناتوانى در قدرت تحليل
تعريف اختلال خواندن بر مبناى ويرايش هنجم راهنماى تشخيصى و آمارى اختلالهاى روانى، حالتى است كه در آن بيشرفت خواندن يايينتر از حد انتظار بر حسب سن، آموزش و هوش كودك است. اين اختلال به ميزان زيادى مانع موفقيت تحصيلى يا فعاليت روزانهاى مىشود كه مستلزم خواندن هستند ( (1). مطالعات متعدد نشان دادهاند 
مىشود. وجود نقص در كاركردهاى اجرايى كودكان نارساخوان حاكى

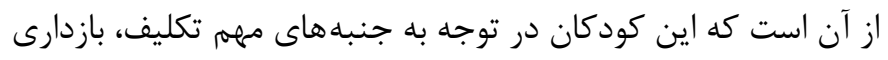

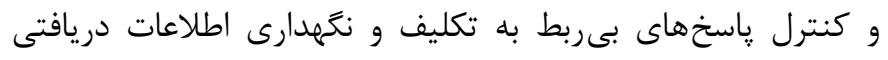

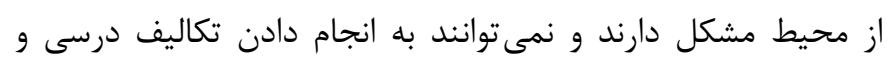

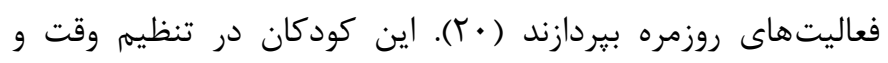

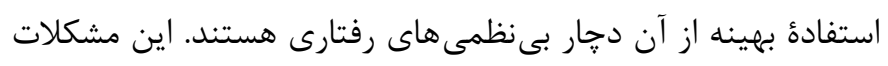

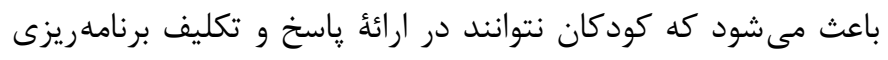
داشته باشند و اجزاى مختلف را به خوبى سامان دهند و يكيار جه كنند

امروزه راهكارهاى مختلفى براى بهبود عملكرد خواندن افراد نارساخوان

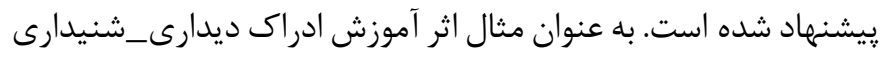

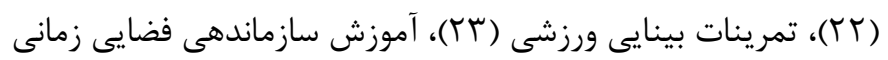

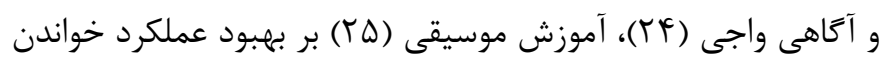

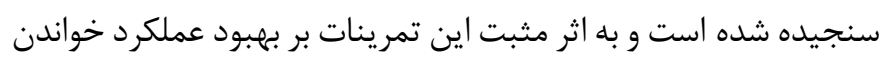

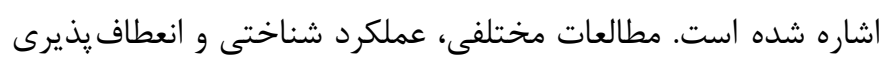

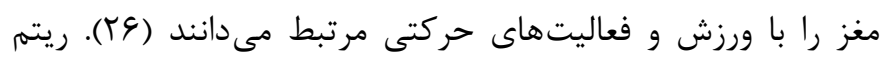

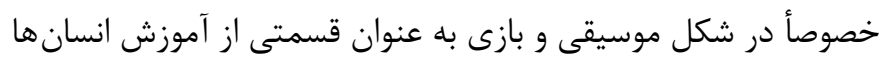

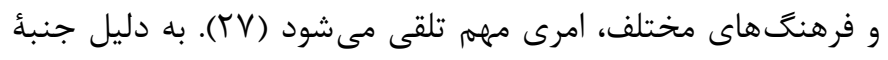

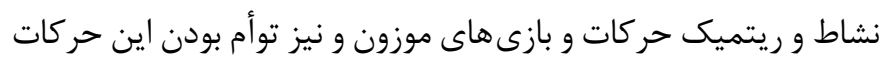
با موسيقى، كودكان بسيارى از مفاهيم و مضامين آموزشى و شناختى

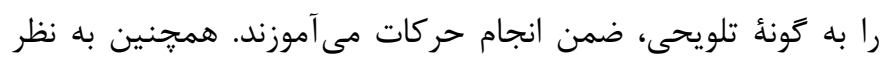

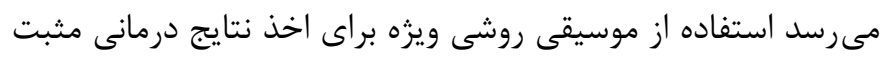

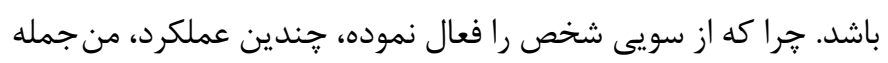

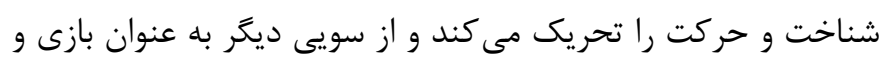

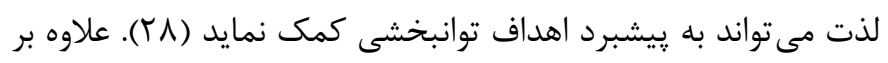

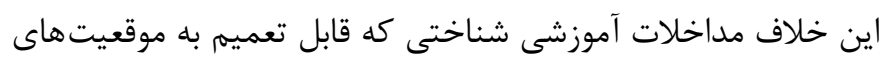

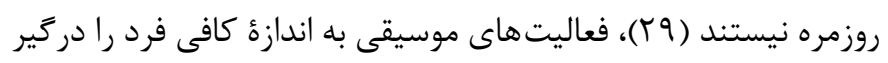

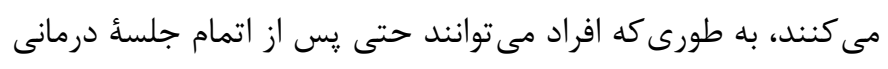

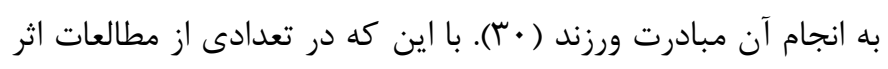

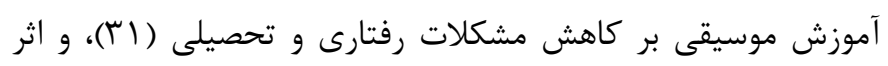

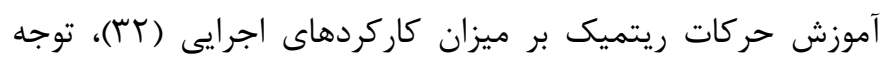

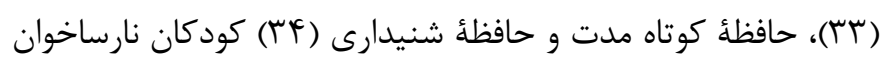

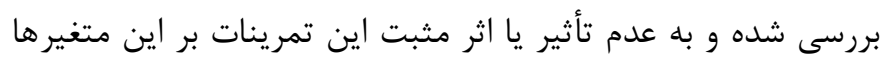

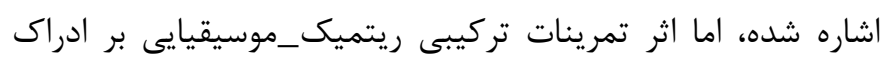

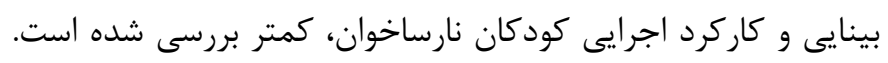

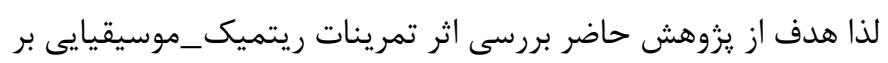
ادراى بينايى و كاركرد اجرايى افراد نارساخوان بود.
و بررسى صحت متن، فقدان توانايى لازم براى تركيب صداها براى

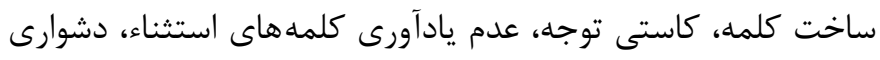
در تشخيص جزء از كل و عدم تمايل به خواندن مى باشد (باّ). دلايل

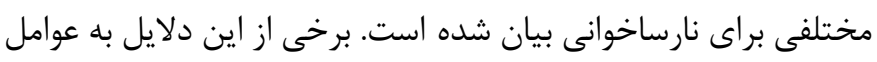

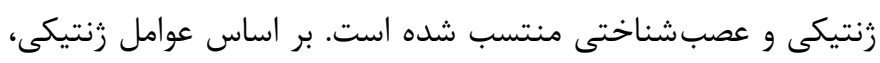

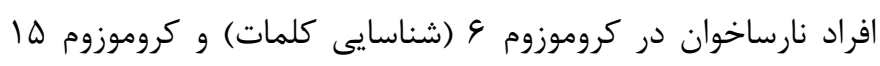

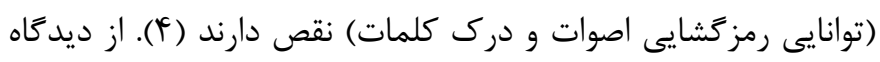

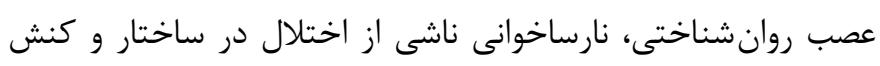

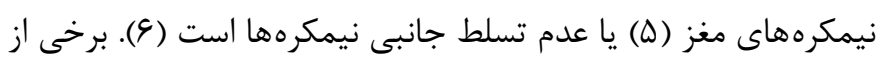
مطالعات نيز به وجود ناهنجارى هايى در سيستم بينايى افراد نارساخوان

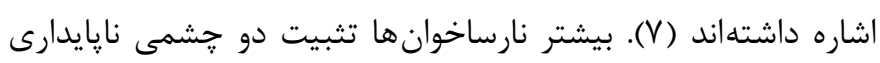

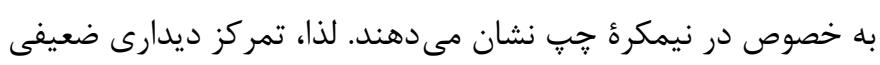

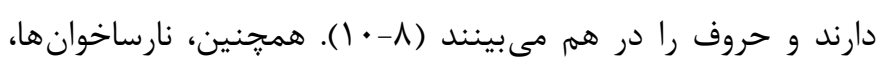

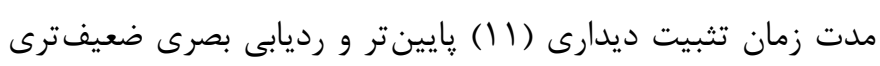

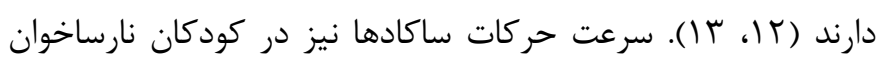

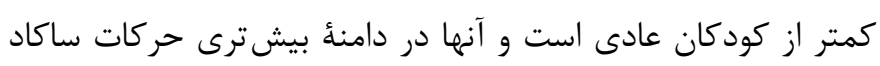

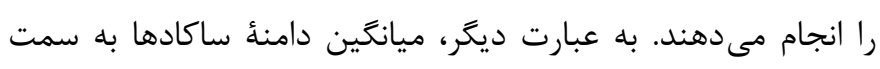

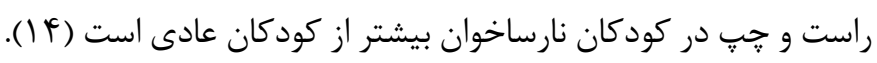

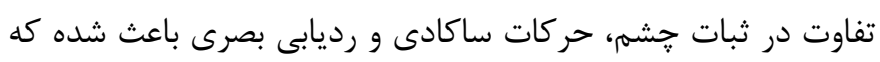

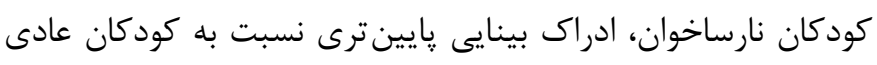

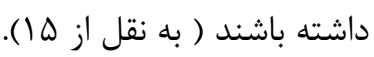

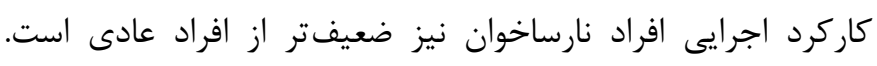

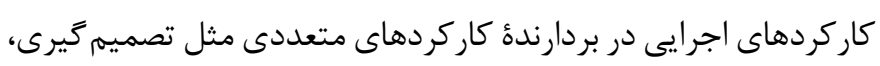

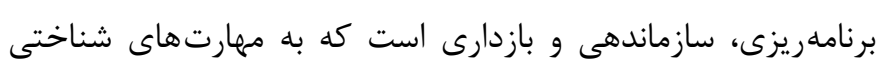

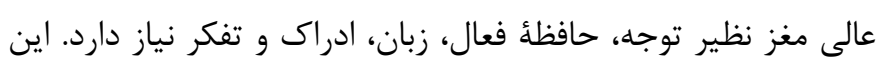

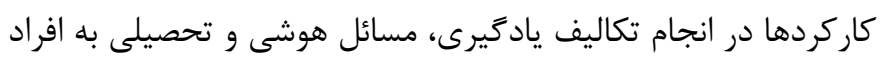

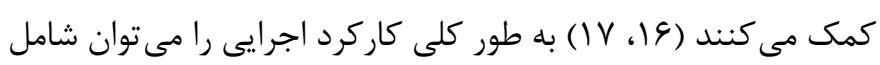

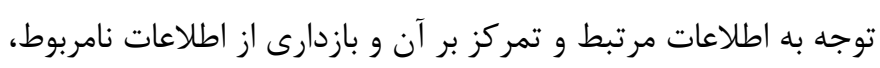

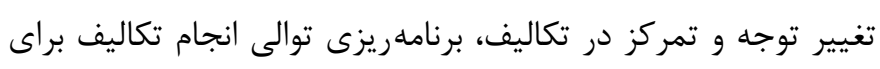

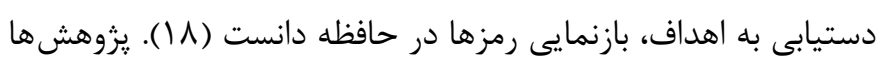

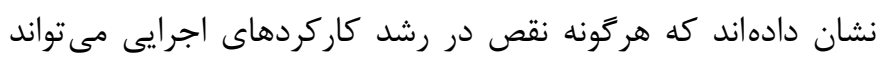

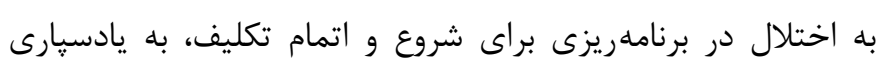

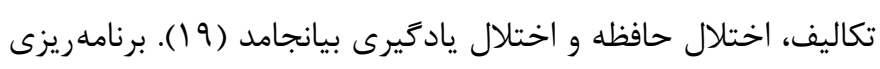

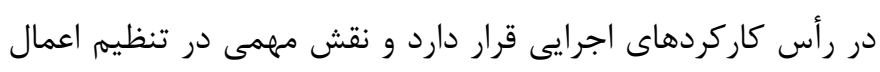

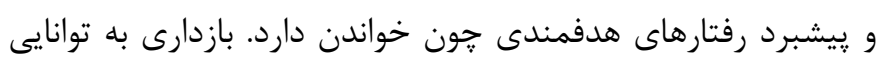

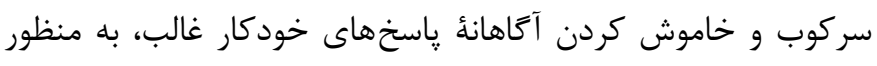

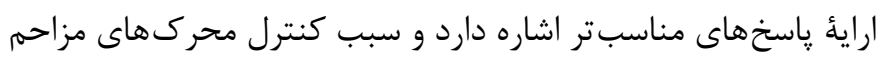




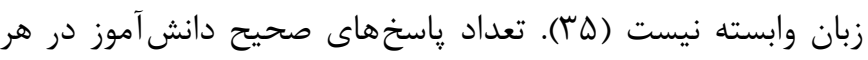

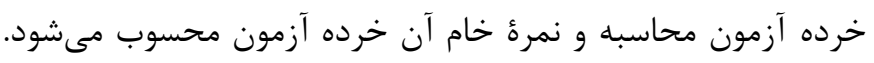

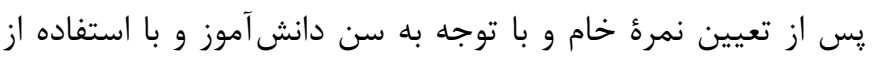

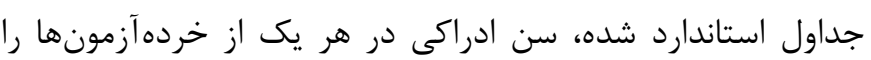

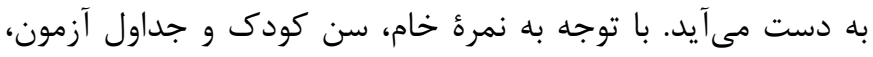

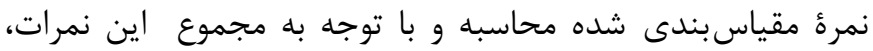
بهرءٔ ادراك بينايى دانشآموز مشخص معىشود.

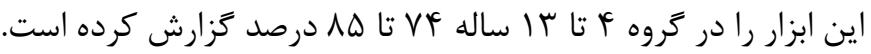

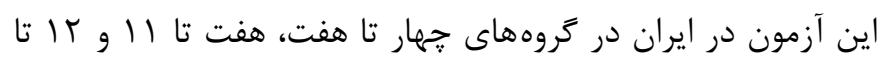

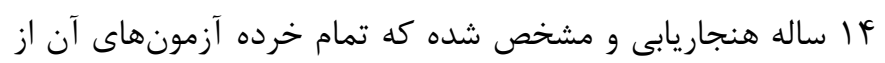
روايى و پايايى برخوردار است (عَ). آزمون دسته بندى كارت ويسكانسين: تاريخجه ساخت آزمون

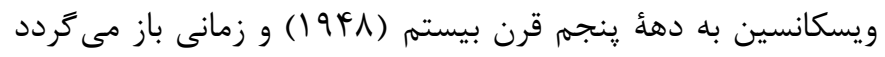
كه Berg مطالعهاى را زير نظر Grant در دانشعاه ويسكانسين آغاز كرد. اين آزمون در اين مطالعه شامل تعداد Y I ا كارت بود كه بر روى هركدام يك الى جهار نماد به صورت مثلث، ستاره، به علاوه و دايره در

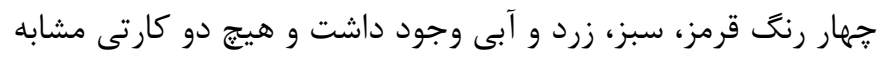

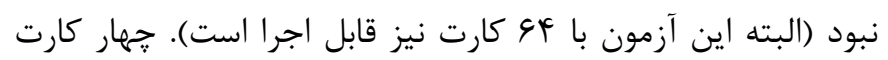

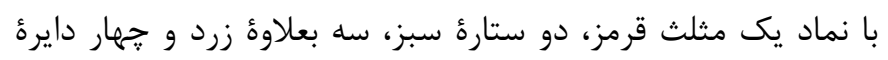

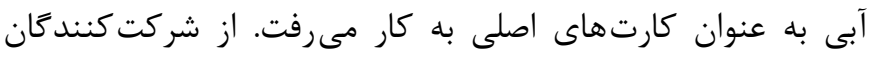

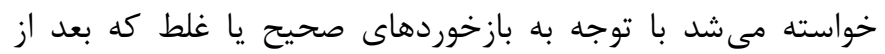

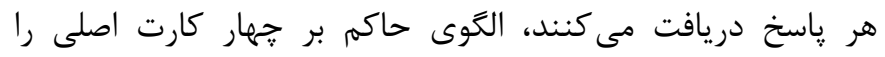

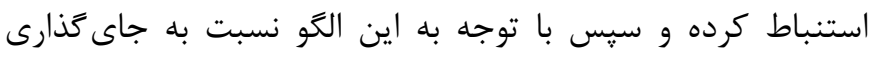

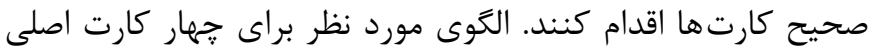

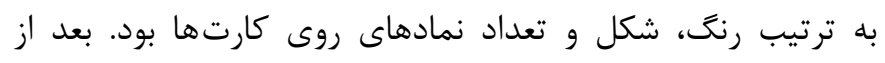

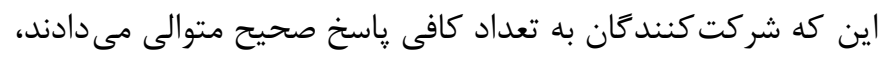

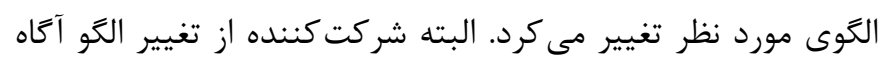

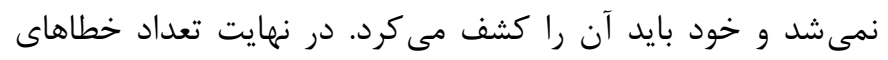

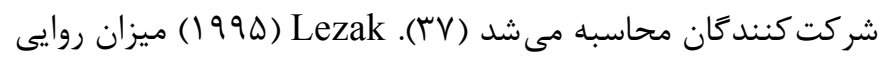

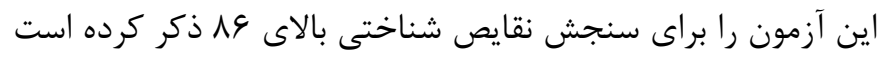

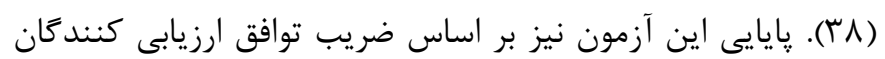

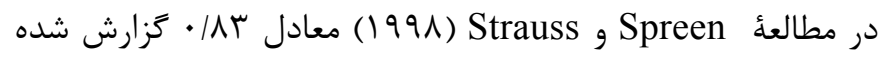

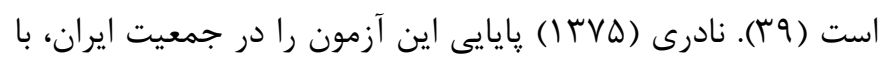

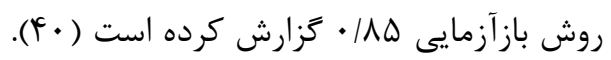

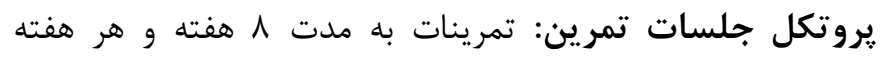

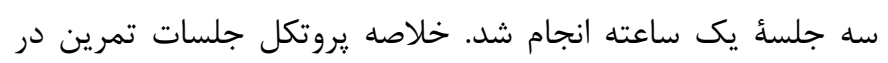
جدول ا آمده است.

\section{ورش كار}

تحقيق حاضر از نوع نيمه تجربى با طرح تحقيق يِش آز آزمون_يس

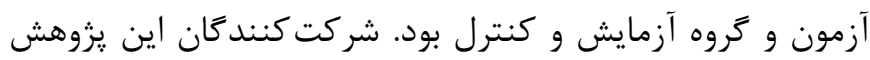

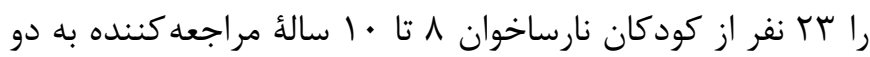
مركز درمانى اختلال يادكيرى شهر اصفهان تشكيل دادند. اين كودكان به صورت در دسترس و هدفمند انتخاب و با همتاسازى

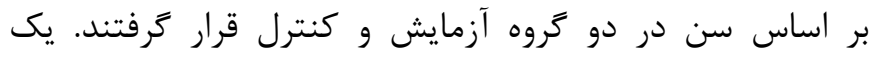

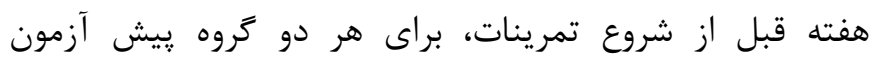

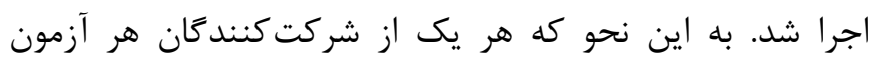

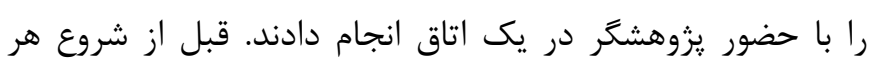

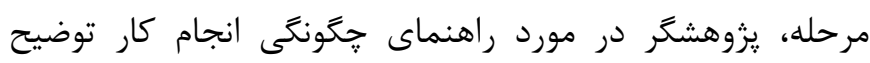

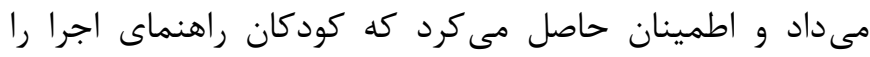

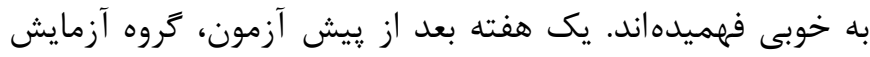
در برنامd م هفتهاى (سه جلسهى يك ساعته در هفته) تمرينات ريتميك_موسيقيايى شركت كردند. گروه كنترل در طول دونه دورة

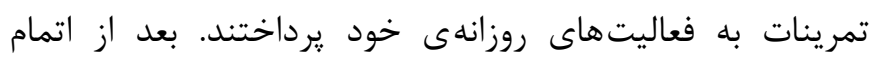

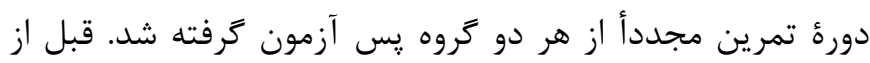

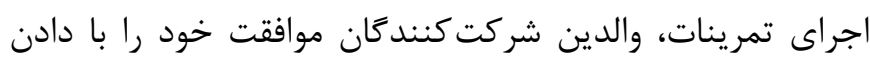
يك رضايتنامه كتبى اعلام نمودند. به منظور جمع آورى اطلاعات،

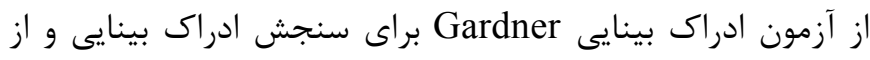

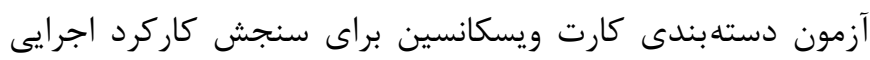
استفاده شد. براى توصيف دادهها از ميانخين، انحراف معيار و جداول

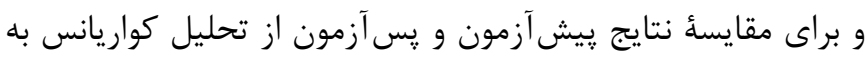

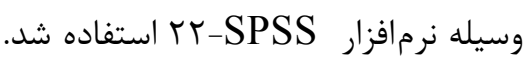
آزمون ادراك بينايى Gardner: از اين نسخه كه Gardner دراد

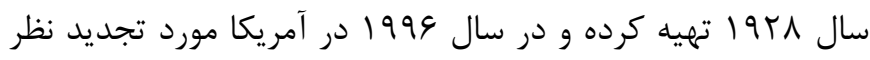

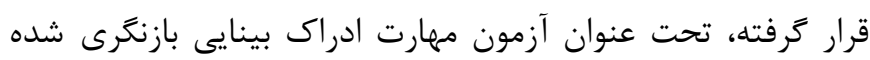
Test of Visual-Perceptual Skills-Revised اين آزمون شامل دو دفترجه است كه يكى از آنها سه و ديكرى جهار

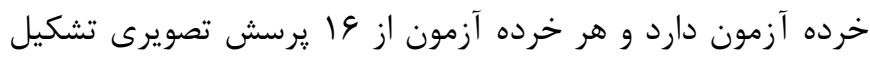
شده است. براى هر مورد اين آزمون، تصويرى به كودى نشان داده آزهان

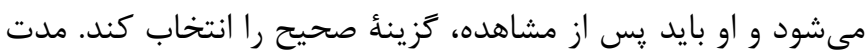

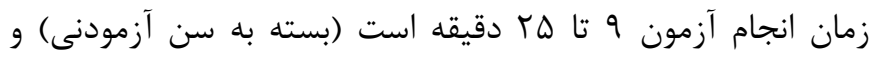

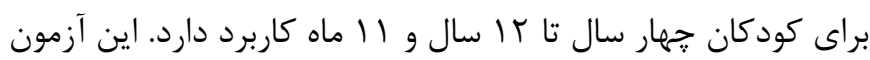

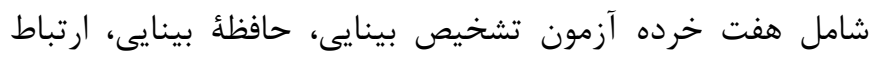

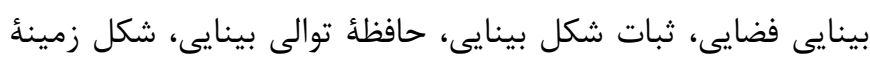

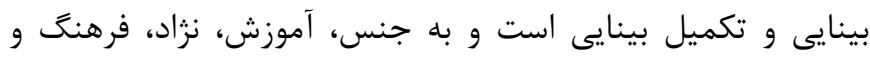




\begin{tabular}{|c|c|}
\hline طرح تمرين & 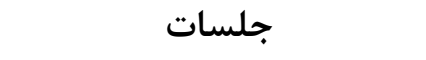 \\
\hline تمرينات بادى پر كاشن (ساز زدن با بدن) & 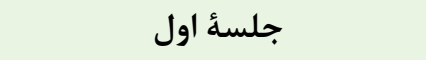 \\
\hline كوبيدن پا به زمين باصداى تميو & 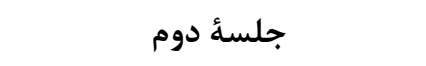 \\
\hline راه رفتن مانند حيوانات (همراه با ريتم كند و تند) & 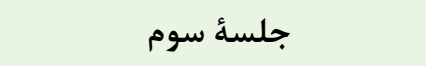 \\
\hline آموزش نتها با كمك از ضرب جوب & جلسةٔ جههارم \\
\hline دست به دست كردن توب با ريتم & جلسةٌ ينجم \\
\hline دست زدن با تغيير ريتم آهنَ توب سفيدم & جلسة ششم \\
\hline با ريتهم آهنَ كود كانه دريبل زدن & جلسةٔ هفتم \\
\hline با ريتم خاصى يك پا و جفت پا به صورت مداوم يريدن & جلسئ هشتم \\
\hline با ريتمهاى متنوعى بر روى طبل يا ميز كوبيدن & جلسة نهم \\
\hline متناسب با ريتم انجام حر كاتى از قبل مشخص شده (نشستن، برخاستن، خرخيدن و ...) & جلسةٔ دهم \\
\hline بازى با حلقهها همراه با ريتم (ريتم تند دور حلقهها تاب خوردن، ريتم آهسته جاكيرى در حلقهها & جلسةُ يازدهم \\
\hline اجراى تمرينات تركيبى (ريتهم تند: دريبل زدن، ريتم آهسته: جابهجايى توّ در دستها & جلسةُ دوازدهم \\
\hline تمرينات دو نفره روبروى هم: باصداى ريتهم دست زدن انفرادى و كوبيدن دست ها به هم، تاب خوردن، دست همديخر را كرفته و & جلسةٔ سيزدهم \\
\hline 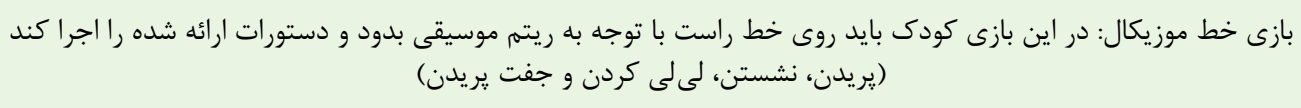 & جلسةُ هانزدهم \\
\hline 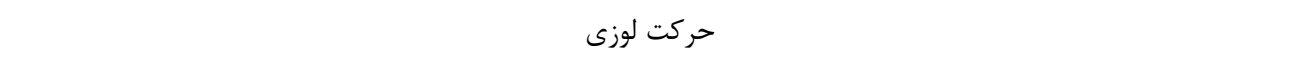 & جلسةٔ شانزدهم \\
\hline بازى صدا: با توجه به صداهاى تخش شده شكل صدا را به نمايش مى كذارد & جلسةٔ هفدهم \\
\hline بازى ميدان اشكال & جلسةٔ هجدهم \\
\hline 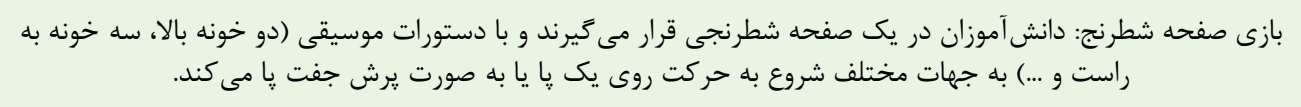 & جلسه نوزدهم \\
\hline 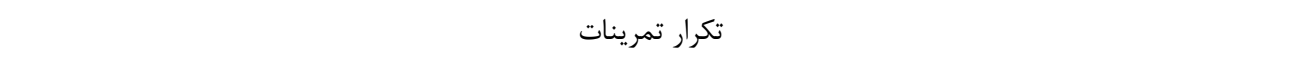 & جلسةٔ بيستم الى بيست و جههارم \\
\hline
\end{tabular}


ادراى بينايى و كاركرد اجرايى كودكان نارساخوان تأثير معنادارى

يافته هاى اين يزوهش در جدول هاى r و ب آورده شده است. داشته است.

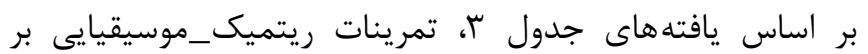

جدول r. شاخص هاى توصيفى متغيرها در گروهها

\begin{tabular}{|c|c|c|c|c|}
\hline \multicolumn{2}{|c|}{ كنترل } & \multicolumn{2}{|c|}{ آزمايش } & تروه \\
\hline يس آزمون & ي ي & يس آزمون & ييش آزمون & \multirow{2}{*}{ متغير } \\
\hline ميانكين 土 انحراف معيار & ميانگين 土 انحراف معيار & ميانگين 土 انحراف معيار & ميانگين 土 انحراف معيار & \\
\hline$F / l \pm g f / V F$ & $F / l \pm \xi F / r \Lambda$ & $11 / \Delta \cdot \pm 1 / \Delta$ & $V \pm 1 / \Delta 9$ & ثبات شكل \\
\hline$\Delta / r \pm G F / \Delta F$ & $\varphi / \varphi \Delta \pm r / 1 \varphi$ & $9 / \Delta \cdot \pm 1 / V \Lambda$ & $\Delta \pm 1 / \wedge \Delta$ & حافظه توالى بينايى \\
\hline$q / \Delta D \pm r / r q$ & $V \pm r / \kappa$ & $1 \cdot / 94 \pm 1 / 94$ & $G / T \Delta \pm r / r r$ & شكل زمينه بينايى \\
\hline$G \pm T / T r$ & $\Delta / \Delta \Delta \pm r / r \Delta$ & $9 / \wedge r \pm 1 / 94$ & $\Delta / / V \pm r / 9 F$ & اكمال بينايى \\
\hline$\Delta \pm r / r r$ & $r / \Lambda r \pm r / 4$. & $\Lambda \pm 1 / v$ & $\Gamma / \Lambda \Gamma \pm T / \widetilde{T}$ & تشخيص بيناييى \\
\hline$r / M \pm T / \Lambda T$ & $\varphi / \widetilde{\varphi} \pm 1 / \wedge \Delta$ & $q / 4 r \pm r / 19$ & $r / 9 r \pm r / V V$ & حافظه بينايى \\
\hline$\varphi / q) \pm 1 / r$. & $\Delta / r V \pm 1 / l$. & q/AT $\pm 1 / \Delta r$ & 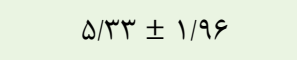 & ارتباط بينايى فضايى \\
\hline $99|\Lambda \pm q| / r V$ & $9 \Delta / V \pm \cdot 9 / 99$ & $9 q \pm V / r F$ & $q V / 0 \cdot \pm 9 / T r$ & ادراك بينايى كل \\
\hline $91 / .9 \pm r \cdot / 1 r$ & $\Delta r / \Delta \Delta \pm I r / V \Delta$ & $V V / \cdot \wedge \pm 19 / 9$. & $F \Delta / \Delta \cdot \pm q / \wedge \gamma$ & كاركرد اجرايى \\
\hline
\end{tabular}

جدول r. برآورد تحليل كوواريانس جهت تعيين اثر تمرينات ريتميك_موسيقيايى بر ادراك بينايى

\begin{tabular}{|c|c|c|c|c|c|c|}
\hline مجذور اتا & $\mathbf{P}$ & $\mathbf{F}$ & ميانگين مربعات & درجه آزادى & مجموع مربعات & منبع تغيير \\
\hline .195 &.$/ \cdot 1 *$ & $r \Delta V / F .$. & $\Delta I \Delta T / V F T$ & 1 & $\Delta I \Delta T / T V F$ & ادراك بينايى \\
\hline - ITMF & . $/$ r T * & $9 / 11 \mathrm{~V}$ & $1911 / 9 \mathrm{kT}$ & 1 & $1911 / 9 \mathrm{Fr}$ & كاركرد اجرايى \\
\hline
\end{tabular}

هدف از تحقيق حاضر، بررسى اثر يك دوره برنامه تمرينى ريتميك_موسيقيايى بر ادراك بينايى كودكان نارساخوان اثر دارد. اين

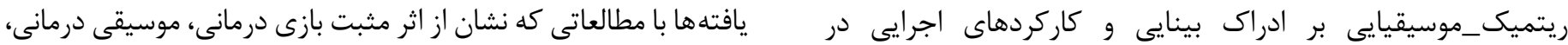
كودكان نارساخوان بود. يافتئ اول تحقيق حاضر اين بود كه تمرينات حركات ريتميكى و تمرينات ادراكى_حركتى بر ادراك بينايى كودكان 
ورزش موجب افزايش سطح يروتئين نوروتروفين مىشود. نوروتروفين مادهاى است كه زنده ماندن و بازسازى سلولهاى عصبى را تقويت مى كند و باعث تقويت، تحريك و رشد نورونها مى شود (1). علاوه بر اين، در تمرينات حركتى ريتيميك_موسيقيايى كودى مؤظف به

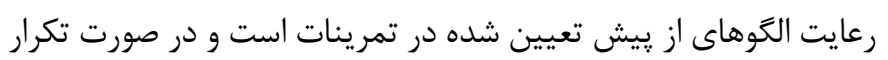

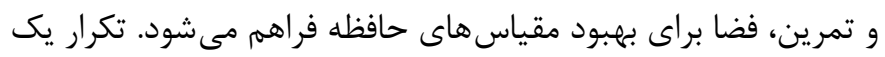

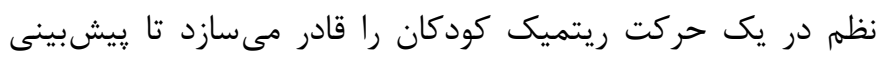
نمايند جه اتفاقى خواهد افتاد و به عبارتى با كمك حافظئ خويش اجزاى بعدى حركت را پِيشبينى مى كنند. در نتيجه سبب تقويت حافظه و كاهش مشكلات آنها مىشود (Tr). Kephart Getman Piaget Gesell ، Baresh

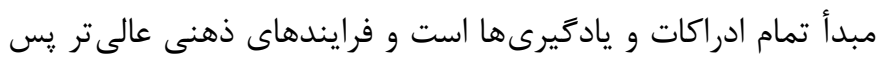

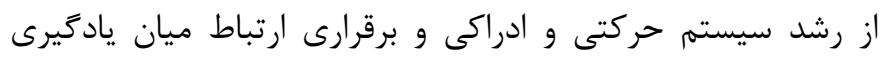

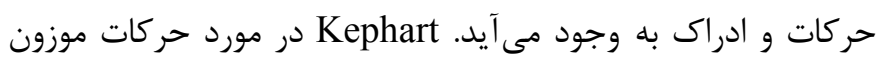

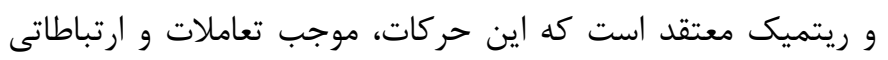

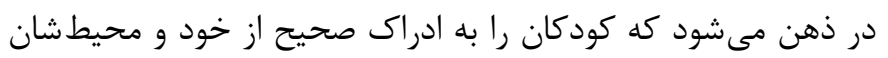

مى رساند (DT).

فرضيه ديكر يزوهش حاضر اين بود كه تمرينات ريتميك_موسيقيايى باعث بهبود كاركردهاى اجرايى مىشود. نتايج يزوهش حاضر نشان داد كه كاركردهاى اجرايى يس از تمرينات ريتميك_موسيقيايى بهبود

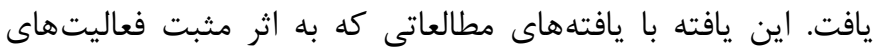

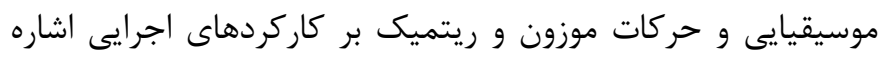

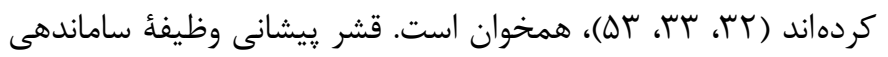

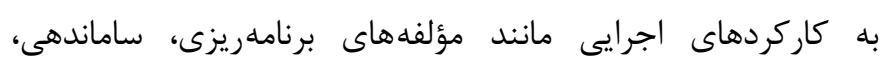

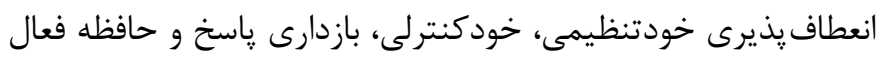

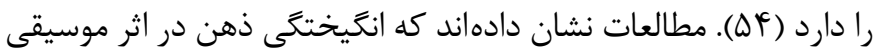
باعث بهبود فعاليتهاى لوب يیشانى و ديخر نواحى قشر مغز مىشود

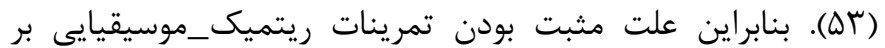
بهبود كاركردهاى اجرايى در كودكان نارساخوان را مى توان به دليل

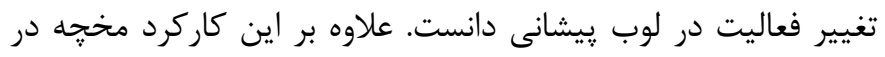

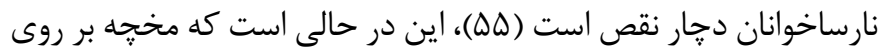

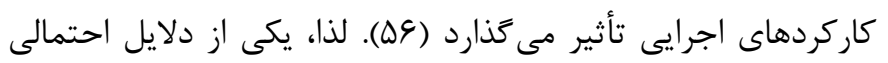

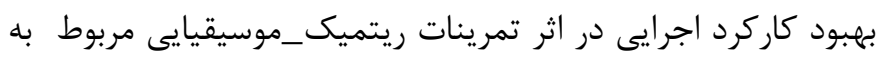
بهبود فعاليت مخجه است. يكى از دلايل احتمالى بهبود كاركرد اجرايى در اثر تمرينات ريتميك_موسيقيايى ممكن است مربوط به متعادل شدن انتقال دهندهاى عصبى از جمله نورايى نفرين، إيى نفرين و دويامين باشد.
نارساخوان دارد، همخوان است (أf-F). در تبيين اين يافتهها مى توان به اثر فعاليتهاى حركتى و فعاليتهاى داراى ريتهم و موسيقى بر افزايش آكاهى فضايى، آكاهى زمانى، جهتئي فيابى، زمان واكنش،

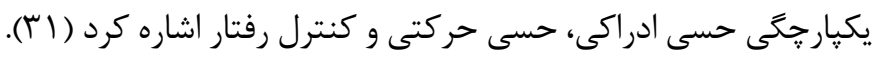

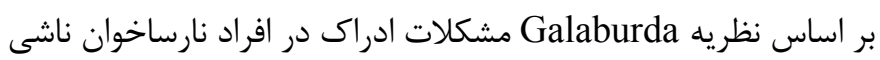

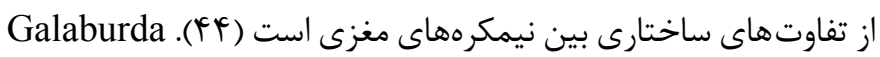

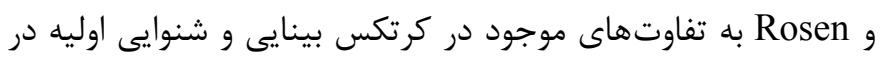
افراد نارساخوان اشاره كردهاند، جايى كه تفاوتهاى موجود در نورونها و الكوهاى تقارن سلولى مىتواند نشان داده شود. يافتههاى اين مؤلفان يك تبيين عصب شناختى براى مشكلات بينايى، شنوايى، حسى و

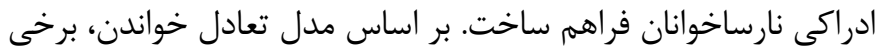

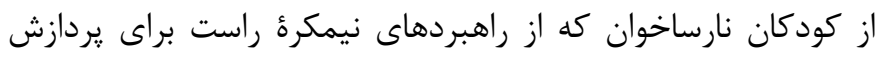
استفادة بيش از حد مى كنند ممكن است از قدرت درك خوبى برخوردار

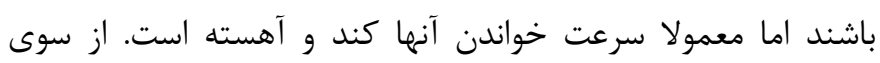

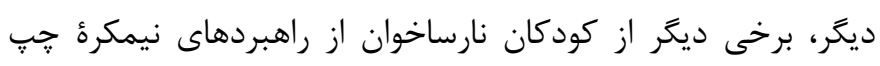

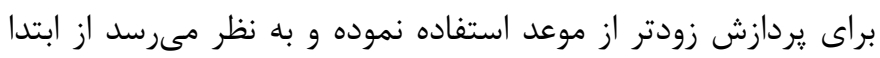

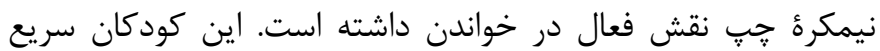
مى خوانند ولى دجار خطاهاى اساسى از جمله حذف، اضافه و جانشينى لنى

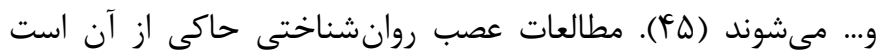
كه موسيقى باعث تعادل يويا ميان نيمكره جٍ و راست شده و منجر به يكيارجهازسى اطلاعات در يس سر، آهيانه و كيجكاه كه مسئول

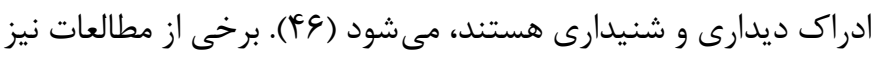

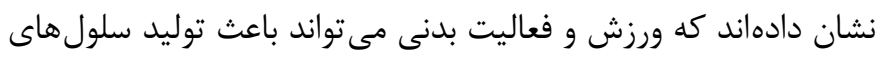

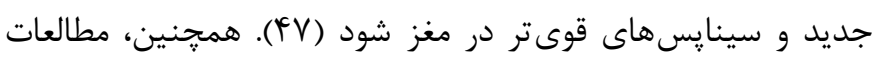

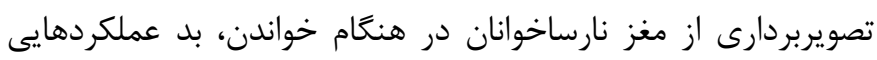

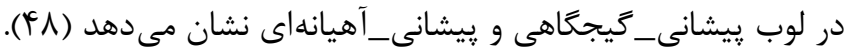
در اثر بخشى تمرينات ريتميك_موسيقيايى بر افزايش ادراك بينايى مى توان كفت، تمرينات حركتى و بازى درمانى جند نقش مههم بازى

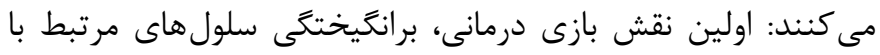

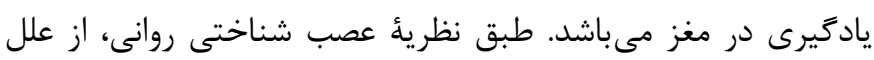

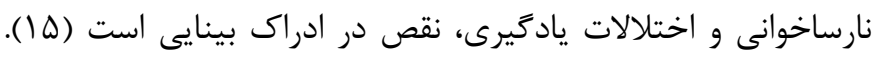

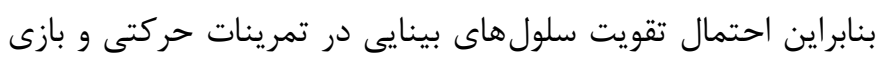

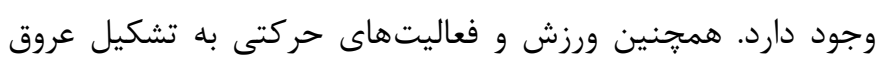
خونى جديد و افزايش سطوح سروتونين منجر مىشود (q)، • (a). به عبارتى در محيط حركتى همراه با موسيقى، خرخههاى ييام رسان عصبى ميان نورونى ايجاد مى شود كه بخشهاى بالاتر سيستم عصبى كه مربوط به حافظه و شناخت است را تحريك مى كند. همجنين، 
حيوان را از حافظه فراخوانى كند و سيس با توجه به آن جه از حافظه

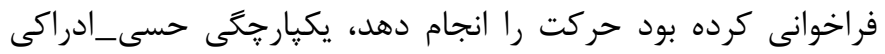
و حسى_حركتى آنها افزايش مى يافت. يكى ديكر از تمرينات، بازى

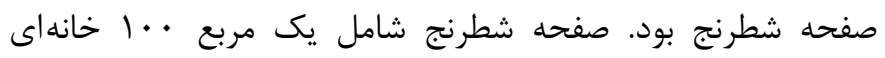

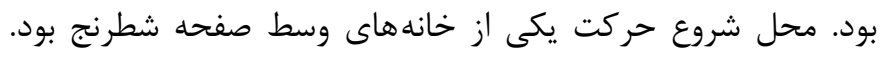
كودى آموزش ديده بود كه با سرعت زيادِ موسيقى سه خانه خانه به سمت

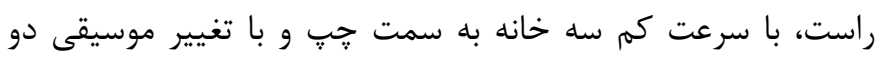

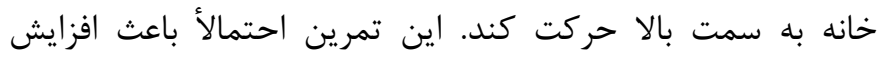
مهارت جهت يابى كودكان مىشد. يكى ديكر از تمرينات اين بود

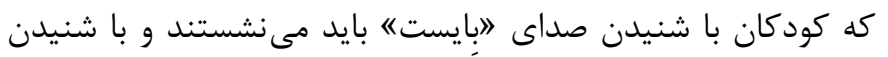

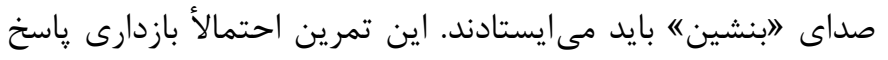

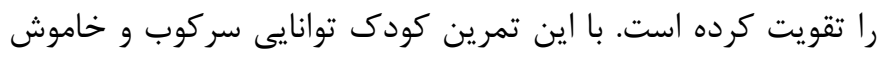

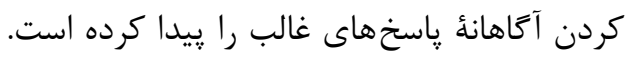

\section{نتيجه كَيرى}

به طور خلاصه يافتهاى يزوهش حاضر نشان داد كه تمرينات

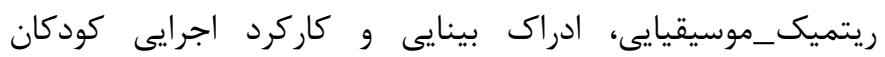
نارساخوان را بهبود مي دهد.

\section{تشكر و قدردانى ت تماد}

از تمام كودكانى كه در اين يزوهش شركت كردند، سياسگزارى مى منماييم.

\section{References}

1. American Psychiatric Association. Diagnostic and Statistical Manual of Mental Disorders 5th Edition:DSM-5®. Arlington VA:American Psychiatric Pub;2013.

2. Kaltner S, Jansen P. Mental rotation and motor performance in children with developmental dyslexia. Research in Developmental Disabilities. 2014;3(35):741-754.

3. Siyah Sayari N. Learning disabilities. Tehran:Modaber;2006. (Persian)

4. Sadock BJ, Sadock VA. Kaplan \& Sadock's synopsis of psychiatry: Behavioral sciences/clinical psychiatry. 10th ed. Philadelphia:Lippincott Williams \& Wilkins;2007.

5. Becker MG, Isaac W, Hynd GW. Neuropsychological
دويامين اصلىترين انتقال دهنده عصبى اثرگذار بر كاركردهاى اجرايى است (DV). مطالعات نشان مى دهند، تمرينات ورزشى باعث تنظيم

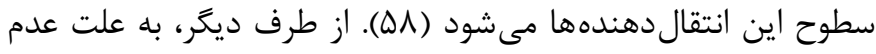
درك صحيح مشكلات نارساخوان، در نارساخوانان احساساتى مانند استرس، اضطراب، افسردگى و عدم اعتماد به نفس، شايع است (99). استرس و اضطراب باعث كاهش كاركردهاى شناختى از جمله توجه و تمركز مى گردد. تمرينات ورزشى با افزايش توزيع و جذب اكسيرن و افزايش ترشح انتقال دهنده عصبى سرتونين باعث كاهش استرس، اضطراب، افسردگى و افزايش هيجانات مثبت مى شود. از طرف ديخر، تمرينات ورزشى با تأثير بر سيستم عصبى خود مختار مقاومت در برابر استرس را افزايش مى دهد. با كنترل اضطراب و استرس، تمركز افزايش

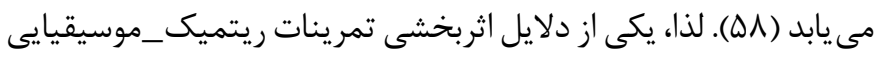
بر كاركردهاى اجرايى را مى توان به بهبود قدرت تمركز و توانايى ناديده كرفتن محرك هاى اضافى نسبت داد. در مجموع، در يروهش حاضر، تمريناتى انتخاب شدند كه علاوه بر داشتن جذابيت و بازى گونه بودن بتوانند بر ادراك بينايى و ورئ

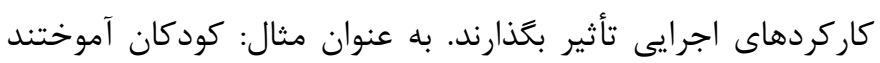
كه با تغيير ريتم (تند، آرام)، نوع موسيقى و نوع تمرين (حركاتى مثل نشستن، برخاستن، جرخيدن و دريبل زدن) خود را تغيير دهند. از طرف ديگر كودك بايد حركت وسيله يا حيوانى (قطار، هوإيما، كلاغ و ..) كه صداى آن يخش مى شد را تقليد كنند. از آن جايى كه كودى مجبور مىشد با توجه به صداى شنيده شده، حركت آن وسيله يا

development of nonverbal behaviors attributed to "frontal lobe"

functioning. Developmental Neuropsychology. 1987;3(34):275-298.

6. Learner J. Learning disabilities: Theories, diagnosis and strategies. 7th ed. San Diego:Houghton, Mifflin-Company; 1997.

7. Zeffiro T, Eden, G. The neural basis of developmental dyslexia. Annals of Dyslexia 2000;50(1):1-30.

8. Stein JF, Richardson AJ, Fowler MS. Monocular occlusion can improve binocular control and reading in dyslexics. Brain. 2000;123(1):164-170. 
9. Bednarek DB, Tarnowski A, Grabowska A. Latencies of stimulus-driven eye movements are shorter in dyslexic subjects. Brain and Cognition. 2006;60(1):64-69.

10. Eden GF, Stein JF, Wood HM, Wood FB. Differences in eye movements and reading problems in dyslexic and normal children. Vision Research. 1994;34(10):1345-1358.

11. Hutzler F, Wimmer H. Eye movements of dyslexic children when reading in a regular orthography. Brain and Language. 2004;89(1):235-242.

12. Pavlidis GT. Do eye movements hold the key to dyslexia?. Neuropsychologia 1981;19(1):57-64.

13. Biscaldi M, Gezeck S, Stuhr V. Poor saccadic control correlates with dyslexia. Neuropsychologia. 1998;36(11):11891202.

14. MacKeben M, Trauzettel-Klosinski S, Reinhard J, Durrwachter U, Adler M, Klosinski G. Eye movement control during single-word reading in dyslexics. Journal of Vision. 2004;4(5):388-402.

15. Same Siahkalroodi L, Alizadeh H, Kooshesh M. The impact of visual perception skills training on reading performance in students with dyslexia. Advances in Cognitive Science. 2009;11(2):63-72. (Persian)

16. Best JR, Miller PA. A developmental perspective on executive function. Child Development. 2010;81(6):1641-1660. 17. Tops W, Callens C, Van Cauwenberghe E, Adriaens J, Brysbaert M. Beyond spelling: the writing skills of students with dyslexia in higher education. Reading and Writing. 2013;26(5):705-720.

18. Harvey PD, Siu CO, Romano S. Randomized, controlled, double-blind, multicenter comparison of the cognitive effects of ziprasidone versus olanzapine in acutely ill inpatients with schizophrenia or schizoaffective disorder. Psychopharmacology. 2004;172(3):324-332.

19. Brocki KC, Eninger L, Thorell LB, Bohlin G. Interrelations between executive function and symptoms of hyperactivity/impulsivity and inattention in. preschoolers: A two year longitudinal study. Journal of Abnormal Child Psychology.
2010;38(2):163-171.

20. Wu KK, Anderson V, Castiello U. Neuropsychological evaluation of deficits in executive functioning for ADHD children with or without learning disabilities. Developmental Neuropsychology. 2002;22(2):501-531.

21. Missiuna C, Rivard L, Pollock N. Children with developmental coordination disorder: At home and in the community. Canada:McMaster University;2011.

22. Magnan, A, Ecalle, J. Audio-visual training in children with reading disabilities. Computers \& Education. 2006;46(4):407425 .

23. Wilson TA, Falkel LJ. Sports vision: Training for better performance. Champaign IL:Human Kinetics;2004.

24. Hedrick WB, Pearish AB. Good reading instruction is more important than who provides the instruction or where it takes place. The Reading Teacher. 1999;52(7):716-726.

25. Tallal P. Improving neural response to sound improves reading. Proceedings of the National Academy of Sciences. 2012;109(41):16406-16407.

26. Goldshtrom Y, Korman D, Goldshtrom I, Bendavid J. The effect of rhythmic exercises on cognition and behaviour of maltreated children: A pilot study. Journal of Bodywork and Movement Therapies. 2011;15(3):326-334.

27. Michalowski MP, Kozima H. Methodological issues in facilitating rhythmic play with robots. In RO-MAN 2007-The 16th IEEE International Symposium on Robot and Human Interactive Communication; 2007 Aug 26; Jeju-do, South Korea. pp. 95-100.

28. Ceccato E, Caneva P, Lamonaca D. Music therapy and cognitive rehabilitation: A pilot study. Music Therapy Today. 2005;6(4):810-821.

29. Bugos JA, Perlstein WM, McCrae CS, Brophy TS, Bedenbaugh PH. Individualized piano instruction enhances executive functioning and working memory in older adults. Aging and Mental Health. 2007;11(4):464-471.

30. Ulfarsdottir LO, Erwin PG. The influence of music on social cognitive skills-A cognitive approach to real-life problems. 
The arts in psychotherapy. 1999;2(26):81-84.

31. Barzegar Bafrooei K, Mirjalili M, Shirahany A. The role of motion games, art and music in reducing behavioral problems in children with learning disabilities. Exceptional Education. 2015;7(135):52-62. (Persian)

32. Dehghani M, Karimi N, Taghipour Javan A, Hasan $\neg$ Nataj Jelodar F, Zeid Abadi F. The effectiveness of rhythmic movement games (weighted) on the rate of executive function in children with neuropsychological learning disabilities. Journal of Learning disabilities. 2012;2(1):53-77. (Persian)

33. Abedi A, Kazemi F, Shooshtari M. Investigation of effects of aerobic exercise on improving executive functions and attention of children with neuropsychological learning disabilities. Journal of Learning disabilities. 2015;4(2):38-54. (Persian)

34. Ghorbanpour K, Pakdaman M, Rahmani M, Hosseini Gh. The effect of rhythmic movement and playing aerobic on shortterm memory functionand auditory memory of students with learning disabilities. Journal of Health Breeze. 2013;1(4):4435. (Persian)

35. Gardner MF. Test of visual-perception skills (non-motor)-revised manual. Belford:Psychological Educational publication; 1996.

36. Siminghalam M, Alibakhshi $\mathrm{H}$. the investigation of motor- free visual perception skills in educable children with developmental coordination disorder in Tehran. Knowledge and Research in Applied Psychology 2012;12(45):71-78. (Persian) 37. Strauss S, Sherman EM, Spreen O. A compendium of neuropsychological tests: Administration, norms, and commentary. 3rd ed. New York:Oxford University Press;2006.

38. Lezak MD. Neuropsychological assessment. 3rd ed. New York:Oxford University Press;1995.

39. Spreen O, Strauss E. Compendium of neuropsychological tests, administration, norms, and commentary. New York:Oxford University press; 1998.

40. Naderi N. Study of Information Processing Some of the functions neuropsychology Patients with obsessive compulsive disorder. [MSc thesis]. Tehran: Tehran Psychiatric Insti- tute;1996. (Persian)

41. Mehri M. The effect of play therapy on enhancing visual perceptual skills of students with learning disorder. International conference on psychology-educational and behavioral sciences. 2016 July 12-13; Tehran, Iran. (Persian)

42. Baghdasariyans A, Poshne K, Hadani A. The effect of music therapy in the Orff style on visual skill and children's eye contact with autistic spectrum disorders. Research in Psychology,2012;6(23):1-23. (Persian)

43. Nesai Moghadam B, Malekpour M, Abedi A, Mafakheri Z. The effective of sand play therapy on visuo-motor perception development in children with educable mental retardation in Isfahan city, Iran. Research in Rehabilitation Sciences. 2012;8(3):553-560 (Persian(

44. Galaburda AM. Developmental dyslexia: A review of biological interactions. Annals of Dyslexia. 1985;35(1):19-33.

45. Galaburda AM, Rosen GD. Neural plasticity in dyslexia: A window to mechanisms of learning disabilities. In James L, editors. Mechanisms of Cognitive Development: Behavioral and Neural Perspectives. 2001. pp 307-323.

46. Reid G. Dyslexia: A practitioner's handbook. 5th ed. Chichester:John Wiley \& Sons;2016.

47. Van Praag H. Neurogenesis and exercise: past and future directions. Neuromolecular medicine. 2008;10(2):128-140.

48. Wolf RC, Sambataro F, Lohr C, Steinbrink C, Martin C, Vasic N. Functional brain network abnormalities during verbal working memory performance in adolescents and young adults with dyslexia. Neuropsychologia. 2010;48(1):309-318.

49. Young SN. How to increase serotonin in the human brain without drugs. Journal of Psychiatry \& Neuroscience: JPN. 2007;32(6):394-399.

50. Isaacs KR, Anderson BJ, Alcantara AA, Black JE, Greenough WT. Exercise and the brain: Angiogenesis in the adult rat cerebellum after vigorous physical activity and motor skill learning. Journal of Cerebral Blood Flow \& Metabolism. 1992;12(1):110-119.

51. Huang T, Larsen KT, Ried-Larsen M, Møller NC, Andersen 
LB. The effects of physical activity and exercise on brain-derived neurotrophic factor in healthy humans: A review. Scandinavian Journal of Medicine \& Science in Sports. 2014;24(1):110.

52. Payne VG, Isaacs LD. Human motor development: A lifespan approach. 9th ed. New York:Routledge;2017.

53. Thaut MH, Gardiner JC, Holmberg D, Horwitz J, Kent L, Andrews G, et al. Neurologic music therapy improves executive function and emotional adjustment in traumatic brain injury rehabilitation. Annals of the New York Academy of Sciences. $2009 ; 1169(1): 406-416$.

54. Stuss DT, Alexander MP. Executive functions and the frontal lobes: a conceptual view. Psychological Research. 2000;63(3-4):289-298.

55. Fawcett A, Niclson R. Dyslexia: The role of cerebellum,
Research on Exceptional Children. 2009;9(3):255-272.

56. Stoodley CJ. The cerebellum and cognition: evidence from functional imaging studies. The Cerebellum. 2012;11(2):352365.

57. Arnsten AF, Li BM. Neurobiology of executive functions: catecholamine influences on prefrontal cortical functions. Biological Psychiatry. 2005;57(11):1377-1384.

58. Lavallee D, Kremer J, Moran A, Williams M. Sport psychology: Contemporary themes. 2nd ed. New York:Red Globe Press;2012.

59. Heiervang E, Lund A, Stevenson J, Hugdahl K. Behaviour problems in children with dyslexia. Nordic Journal of Psychiatry. 2001;55(4):251-256.

13. Biscaldi M, Gezeck S, Stuhr V. Poor saccadic control correlates with dyslexia. Neuropsychologia. 1998;36(11):1189-1202 